\title{
Coherence and Sense of Coherence: Conditions for Students' Knowledge Development in Blended Learning Environments
}

\author{
Susanne Dau \\ University College North (UCN) \\ Aalborg University, Department of Communication, Denmark
}

\begin{abstract}
Constraints in the implementation of models of blended learning can be explained by several causes, but in this paper, it is illustrated that lack of sense of coherence is a major factor of these constraints along with the referential whole of the perceived learning environments. The question examined is how activating of models of blended learning in undergraduate education for teacher and radiograph affects the knowledge development. This is approached by mixed methods. The empirical data consist of data from surveys as well as focus group interviews and some observation studies. These data are analyzed and interpreted through a critical hermeneutical process of prefiguration, configuration and re-figuration. The findings illustrate significantly importance of sense of coherence among participants as a condition for implementing new designs and new learning environments. It is revealed that sense of coherence is both related to conditional matters as learning environments, structure, clarity and linkage but also preconditioned matters and prerequisites among participants related to experiences and convenience. It is stressed that this calls for continuous assessment and reflections upon these terms and conditions if the student shall be able acquire the necessary competencies.
\end{abstract}

\section{Introduction}

Knowledge development is an important area of research in connection to introduction and development of models for blended learning, since several studies indicate that it is essential that students are given the opportunity to acquire the competences to do so, in a modern and not static society constantly evolving and requiring continuous knowledge development [1][2]. It means that competences have been given a prominent role in the descriptions of what students should be able to achieve throughout the program [2]. In teacher and radiography education in Denmark students have to achieve competences to develop the profession and their practice. At University College North (UCN) the integration of information technology in the blended learning program is argued to support students learning and knowledge development.
The potential of blended learning in higher education, particularly when viewed in the learning process and learning outcomes as the primary, is confirmed by several studies [1] [3]. Studies stresses, that the development of knowledge can be achieved through the use of blended learning in an educational context. It has for example been assumed that CSCL as part of blended learning will support social cognitive processes of sharing of knowledge and knowledge building [4]. In the matter of the learning and learning outcomes also comparative studies illustrate evidence, that there are several advantages of blended learning compared to more traditional forms of teaching [1]. Potentials as empowerment and joint development are documented, but at the same time, studies point to stress factors related to communication and learning spaces in distanced and blended courses [5] [6]. Other studies point out, that students who is not familiar with the use of technology can experience anxiety, fear and frustration [7]. A survey conducted by Garrison and Vaughan of students feedback on the most effective and least effective performance of ICT in blended courses clearly showed, that the top scorer of the least effective course turned out to be those, where there was no clear expectations, structure, organization and direction [8]. As the knowledge development is influenced by perceived lack of coherence in process of implementation of blended learning, it becomes of significant relevance to reveal the circumstances around the sense of coherence in this process.

I will therefore enlighten the latter by elucidating of empirical data, but first a short introduction to the theory in use, the case as well as design and methodology of research underlying this, aiming to answer the research question and here particular: How is sense of coherence perceived among students and to what extend does it influences learning and knowledge development among student?

\section{Why coherence matter in education and blended learning}

Coherence is a concept which it hard to define, some authors suggest that coherence is something never accomplished but something to strive against continuous for instance as the alignment of ideas and learning opportunities [9]. 
Coherence is in general identified as both conceptual and structural. Conceptual in relation to central ideas and values of individuals involved in the education and structural in the matter of design and structuring of the learning activities across setting [9]. However, resent research broaden the perspective by adding biographic coherence [10]. Bibliography coherence from pre-enrolment experience, as personal knowledge and experiences from participating in prior learning-environments, matters for the sense of coherence among students.

Coherence is in educational research is often advocated as a solution to solve the assumed theorypractice gab or the fragmentation between different kinds of learning and knowledge-epistemologies in college and in placements in internship. For example is it stressed that student teachers finds it difficult to apply knowledge from the program into workplace practice [11] and disconnection seem to a consequence. However, this disconnection and these fragmentations are further complicated in blended learning environments where online learning adds an extra dimension to the complexity.

Albeit coherence is described as contributing to the general challenge of fragmentation it remains unexplored in undergraduate's blended learning education especially with regard to the perspective of students.

In general, there is little empirical research on the nature of coherence and how programs develop coherence [9] and particularly undergraduates' blended learning programs seems to be underexposed in today's research. A longitudinal study of coherence among four professional groups indicated that coherence have a significant impact on students' knowledge and skills [10] why it becomes of significant relevance to elaborate coherence and sense of coherence in implementation of new designs as blended learning as it might influence the knowledge development of students.

\subsection{Sense of coherence related to knowledge development}

Antonowsky argue for salutogenesis ${ }^{1}$ and define SOC as: "a global orientation that expresses the extent to which one has a pervasive, enduring though dynamic feeling of confidence that (1) the stimuli deriving from one's internal and external environments in the course of living are structured, predictable and explicable; (2) the resources are available to one to meet the demands posed by these stimuli; and (3) these demands are challenges, worthy of investment and engagement." [12, p. 19].

In this research I argue for the use of Antonowsky's [7] theory of sense of coherence

\footnotetext{
${ }^{1}$ The word salutogenesis has its roots in the Latin 'salus' or 'salis' meaning health; and the Greek 'genesis' meaning origin.
}

(SOC), since there are several studies that spell out the stress and coping is a factor that should be taken into account in the organization of a blended learning course [6]. However, I am well aware that it is prepared for use in another context namely health science.

The theory is manufactured and tested in several heaths educational contexts and withdraws three key concepts in relation to the individual's ability to cope with stress, namely; manageability, comprehensibility and meaningfulness. SOC is related to general resistance resources as coping strategies, social support, identity, cultural stability etc., and is both shaping outcome and is shaped by life experiences in a balance between under-load and overload. SOC reflects a person's respond to a stressful situation and is a high validated theory [13].

SOC has in the recent years been applied in a smaller scale in educational research; however, the use has primarily been to the matter of students' health and health risk and how their level of SOC is related to their coping. For instance a study of Swedish college students, conducted by Darling, McWey, Howard and Olmstead [14] revealed how some student are in high risk of stress and others are in low risk depending on their ability to cope with changes in their living conditions. The researchers suggested that that salutogenesis resource is important for students coping with stressors. The authors moreover suggested further research on educational institution role in this matter. I will take up this challenge by looking at students SOC in relation to their experiences with blended learning environments in undergraduates' education. An experience that is not only elaborated by students but also by their lecturers, their supervisor practitioners in internship. Thereby is multifocal perspectives applied to investigate student SOC in blended learning environments.

I claim that the theory is of importance in implementation of new designs and models in educations. Despite the fact that the students are not affected by diseases, they are still in a situation where stress and anxiety is underlying.

SOC and students coping is significant, as it regards the individual's ability to handle new situations where transformative learning is acquired. Transformative learning might involve stressors, as it means a change in identity [15] and thereby a thread towards the stability of the self and thus the resistance resources. On the other hand it is learning, involving internal learning processes as well as external interaction processes [15], which are acquired if students should be qualified for knowledge development of the profession, as learning and knowledge development cannot be separated. The qualifications acquired to develop knowledge in the profession involve metacognitive skills, reflection and strong academic competences. 
Those are qualifications, that are developed through transformative learning and in a balance between under-load and overload, or as Vygotsky [16] mentions it; in the zone of proximal development.

I will enlighten the circumstances around this matter by elucidate of the empirical data, but first a short introduction to the case.

\section{The case - implementations of models of blended learning at University College North (UCN), Denmark}

Two undergraduate programs at UCN should implement models of blended learning in autumn 2012 at education of radiography and at teacher education. The aim of the implementation of blended learning at UCN was to achieve more mobility among student in rural area by offering educations in a more flexible form, by use of blended learning. Students were offered part time study at home or at educational stations nearby home and part time at $\mathrm{UCN}$ in the main city of Aalborg. Also periods of placement training in practice could take place near their home city (a secondary purpose was to maintain and develop a competent workforce in rural areas). The target groups were therefore adult students situated in rural area, with strong connection to the local place, but those admitted to the education turned out to be younger and more mobile than expected. Therefore the use of the educational stations in rural areas wasn't taking into use, as most student moved towards the main city or preferred to study from home, when they did not participate at UCN. The particular settlement of the models was developed by lecturers associated the educations.

Among the two educations there were some differences. In education of radiography, they had traditions of settlement of blended courses, as the education has always had an intake from large areas of the country. I was otherwise in teacher education. They had a long tradition of face-to-face instruction, even though one of the lecturers had some experiences of on-line educations related to a specific Flex-teacher education. So, in teacher education the lecturer with experiences of Flexteacher education was together with a traditional lecturer in the planning of the model of blended learning. Otherwise in radiography, all lecturers were involved in the development. The models of blended learning was characterized by these differences, as the teacher education model seemed more fragmented and related to certain disciplines and subjects, where in radiography the whole course were planned as a blended coherent process.

Despite the differences the participants in both educations experienced difficulties with coherence. I the next section I will reveal how these findings are retrieved.

\section{Design and methodology}

This research is conducted as a follow up on the implementation of models of blended learning, with the use of case study and a pragmatic approach of mixed methods, where the qualitative parts has the highest impact. The design consisted of: One survey, seven focus group interviews and three observation studies.

\subsection{Survey}

The data collection of survey was conducted as on-line questionaries' structured primary around the Likert scale supplemented by open rubrics in which student could add comments. The survey-questions were grouped around three main areas, where the first two partly elaborated bibliography matters: 1) background information as prerequisites, 2) learning preferences and 3) students use or intentions of use of educational stations as a supplement to existing learning environments.

The survey was posted to all students $(\mathrm{N}=59)$ in the two educations after it had been pilot tested among student and revised accordingly. This took place after three month of students' enrolment.

There was a respond rate of $66 \%(n=37)$ after two rounds of notifications.

\subsection{Focus-group Interviews}

Focus-group interviews were conducted after a half year of students' enrolment. Those were chosen to obtain detailed information about informants individually and shared perceptions and opinions of the blended learning program.

Focus-groups is well suited for investigating informants opinions on such complex matter revealing experience's, feeling and attitudes towards the matter of blended learning. Focus-groups thereby provide broad range of co- constructed information revealing how different groups think and feel about the theme or subject, in this case blended leaning.

The selection of student informants took into account; variation in gender and area of residence. The choice of lecturers, practitioners and mentors was made on behalf of their involvement in the blended learning program.

Seven focus group interviews were conducted with, respectively; students at each education, lecturers at each education, practitioners at each education and mentors connected to the educational stations. The majority of the groups consisted of 4-8 informants.

All focus-group interviews were organized in well know 'surroundings' and with a narrative approach by use of themes and open ended questions. 
Three main areas was explored; the informants experience and sense of blended leaning, the informants' opinion on how blended learning influence or might influence student knowledge development and their gaining of competence to develop the profession and finally, how the different learning environments and spaces make influence on these matters. Expressed opinions was explored for validation among the informants, however, disagreement were also illuminated without judging.

In the conduction of interviews were taking considerations of confidentiality and was ensured that everybody was heard in a fair manner.

Each interview lasted about one hour and was audio-recorded. All interviews were fully transcribed by the researcher.

\subsection{Observation studies}

Observation studies were done tree times, lasting from two to six hours taking notes continuously. All participants participated voluntarily in the observations.

Observation was made of courses of evaluation in teacher education and of teacher students at a municipal school. Two sessions of tripartite talks and one session of a student lesson with sixth grade students was observed at a municipal school. Furthermore two observations of two hours were made at UCN observing the evaluation of the blended learning approach in teacher education.

Field notes were immediately written down under observations for later use of analysis and interpretation.

\subsection{Analysis and interpretation}

The analysis and interpretation were structured by a critical hermeneutical approach, founded in Ricoeur's [17] use of the hermeneutic arch. Empirical data were analyzed and interpreted by prefiguration (mimesis 1), configuration (mimesis2) and re-figuration (mimesis 3 ). In the pre-figurative analysis the text derived from the empirical data appears in its unstructured form with facts, quotes, metaphors and sentences. In configuration these data are structured around plots and includes metaphors, where parts of the empirical data are put into orders as a kind of thematizations around main plots as a first distanciation. Finally, re-figuration adds further distance by use of critical perspectives and explanations. In re-figuration the interpretation point towards a yet unknown future, still referring to the pre- and configurative parts, but in a more fictive and still validated manner.

\section{Analysis and interpretation}

The analysis is structured around the tree levels of mimesis as mentioned above, but as this paper has limited space only data related to sense of coherence regarding learning and knowledge development are retrieved.

\subsection{Pre-figuration and configuration - mimesis 1 and 2}

Table 1 illustrates the pre-figurative and configurative part, and below table 1 the refigurative interpretation appears. The narratives configured around the plots are illustrated in short sentences in the second column as short of table 1 . These plots refers to the whole of the empirical data, but fully narratives will not appear in this article, as these take up too much space which is beyond this papers extend. The quotations (table 1, column 1) are retrieved from focus group interviews (FG), survey (SV) and the observation study (OS).

Table 1: The analysis and interpretations as prefiguration and configuration

\begin{tabular}{|c|c|}
\hline Pre-figuration - mimesis 1 & $\begin{array}{l}\text { Configuratio } \\
\mathrm{n} \text { - mimesis } \\
\text { 2: Main plots } \\
\text { and plots } \\
\text { below }\end{array}$ \\
\hline $\begin{array}{l}\text { FG: "Here at UCN you are } 100 \% \text { focused, at } \\
\text { home only } 10 \% \text { " (Teacher students, p. 32) } \\
\text { “ ... so many thing are lost, if you just sit (using } \\
\text { Skype)...I wouldn't feel that I have a team, and I } \\
\text { wouldn't feel, that I belong to the team" } \\
\text { (Teacher students, p. } 31 \text { ) } \\
\text { FG: "Sitting at home... there are things that } \\
\text { constantly distracts you" (Student radiography } \\
\text { p.9) }\end{array}$ & $\begin{array}{c}\text { Environments } \\
\text { matters } \\
\text { - Focus } \\
\text {-Distraction }\end{array}$ \\
\hline $\begin{array}{l}\text { FG: "It means a lot, how you are introduced" } \\
\text { (Teacher students, p. 40) } \\
\text { "You've got to be entrepreneurial and create } \\
\text { some structures ... do some things that needs to } \\
\text { be addressed in period of study....if we do not } \\
\text { set frames, as we have done here, the afternoon } \\
\text { series on television takes their attention" } \\
\text { (Lecturer teacher education, p. 24) } \\
\text { "They (students) are just started and should be } \\
\text { taken care of, and there must be structure" } \\
\text { (Lecturer teacher education, p. 25) } \\
\text { "It demands (discussion on-line), that you as } \\
\text { lecturers structure it, and gives them (students) } \\
\text { deadlines and tasks,...it demands imposing } \\
\text { requirement" (Lectures at education of } \\
\text { radiography, p. 13) } \\
\text { "So it about ... structure and connections" } \\
\text { (Lecturers at education of radiography, p. } 21 \text { ) } \\
\text { OS: "We need better introduction to lecturers } \\
\text { and events" } \\
\text { "There need to be more conversations among } \\
\text { lecturers about the planning of lessons" } \\
\text { "We need to know the purpose of the education } \\
\text { and lessons before the holding" } \\
\text { "It works well with a well-planned schedule" } \\
\text { "We need a continuous thread in the subjects } \\
\text { and courses" }\end{array}$ & $\begin{array}{c}\text { Structure } \\
\text { matters } \\
\text {-Naming } \\
\text { and framing }\end{array}$ \\
\hline
\end{tabular}




\begin{tabular}{|c|c|}
\hline $\begin{array}{l}\text { SV: "It is (blended learning) fine, but also } \\
\text { confusing. We still really don't know what } \\
\text { FlexVid is" } \\
\text { FG: "I feel the letter vas in Russian (letter } \\
\text { regarding FlexVid) and after the four first } \\
\text { sentences, you gave up" (Teacher students, p. } \\
\text { 33) }\end{array}$ & \\
\hline $\begin{array}{l}\text { FG: "I think the problem is, that we didn't know, } \\
\text { whether it was proper (the assignment), it just } \\
\text { had to be done" (Teacher students, p.5) } \\
\text { "It is difficult, if the teacher doesn't 'puts it in a } \\
\text { nutshell'... I think he (lecturer) makes far too } \\
\text { open tasks, it put obstacles to us, he might limit } \\
\text { it a bit" (Teacher students, p.7) } \\
\text { OS: "Cannot find the assignments and } \\
\text { homework at the learning platform" } \\
\text { "Avoid confusion around homework and task in } \\
\text { subject we haven't been taught about" } \\
\text { "Cut it 'in a nutshell", }\end{array}$ & \\
\hline $\begin{array}{l}\text { FG: "So I was very puzzled at first, ... what } \\
\text { should we use it for" (Student radiography p. 20) } \\
\text { "It frustrates me, that this project (educational } \\
\text { stations) seems invisible" (Mentors, p.12) }\end{array}$ & \\
\hline 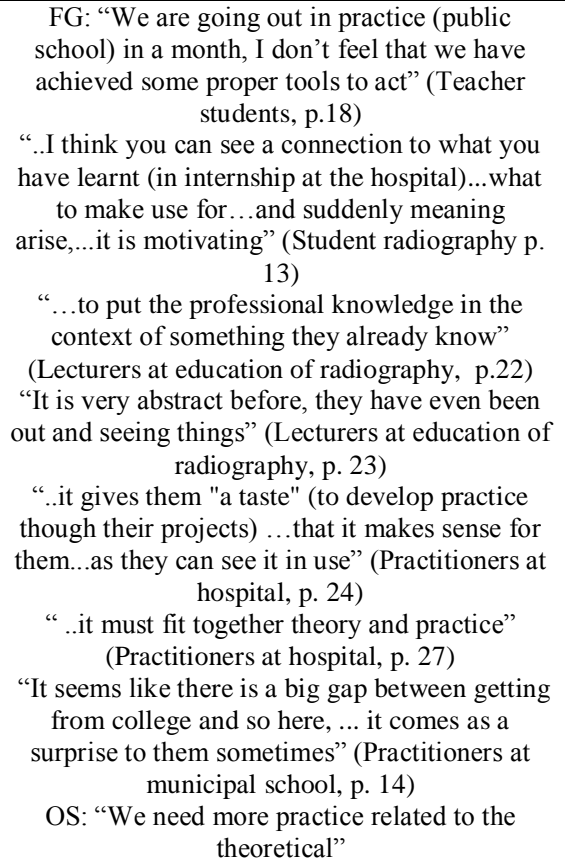 & $\begin{array}{c}\text { Linkage } \\
\text { matters } \\
\text {-Linkage of } \\
\text { theory and } \\
\text { practice as a } \\
\text { matter of } \\
\text { understanda } \\
\text { bility }\end{array}$ \\
\hline $\begin{array}{l}\text { FG: "It is more easy to have a conversation in } \\
\text { here (UCN),...I get so annoyed using } \\
\text { technic...yes, and you are used to it (meting face- } \\
\text { to-face) form high school.... kind of security in } \\
\text {..(studying at UCN)" (Student radiography, p. 7) } \\
\text { "I think when you come here as a freshman ... } \\
\text { referring only back to how one's own teaching } \\
\text { has been" (Practitioners at municipal school, } \\
\text { p. 10) }\end{array}$ & $\begin{array}{l}\text { Experiences } \\
\text { matters } \\
\text {-Referential } \\
\text { self }\end{array}$ \\
\hline
\end{tabular}

\subsection{Re-figuration - mimesis 3}

The re-figurative interpretation point in a whole toward SOC as a matter of condition for learning and further as a foundation of professional knowledge development.

The re-figurative interpretation is pointing towards the future by adding empirical and theoretical explanations and by the use of critical perspectives. The re-figuration is structured around the main plots as they appear in table 1 column 2 .

5.2.1 The learning environment. Regarding the environment and spaces of learning, there seems to be a high priority of face-to-face environment as a meaningful and manageable learning environment Otherwise, the management of studying at home is disrupted, as the environment might afford other kinds of daily living activities. The processes of learning is thereby primary linked to UCN, as this institutions offers space for both focusing and a sense of belonging: "Here at UCN you are $100 \%$ focused, at home only $10 \%$ " and "...so many thing are lost if you just sit (using Skype)...I wouldn't feel that I have a team, and I wouldn't feel that I belong to the team" (Teacher students, p. 31-32). It is clear that online activities are not perceived as meaningful as face-to-face activities and that is difficult for students to achieve manageability online and at home. There are reservations to the demands, and studying at home seems limited as students' investment and engagement in these activities are minimized.

The students seem to experience a kind of disconnection when they are to study at home and there might not be biographic coherence that they can rely on, since home is perceived as a space for other activities of daily living. The lack of focusing in use of on-line media at home is to some extend explained by the distractions in the environment, but this is a matter of concern as students might cut themselves off some essential competences to manage self-directed learning and transformative learning, if they from the beginning of the courses dismiss it as a place for self-paced and on-line learning.

On the other hand the learning environment in classroom at UCN is a familiar space for learning activities and students are more committed, engaged and motivated when they are there. There is bibliography coherence as students in general have experiences of participating in these kinds of spaces both high schools and municipal schools during previously educations.

5.2.2. Structure. In the matter of structure, it seem to be significant, that students' sense of coherence is dependent on a clear structure in planning and organization of the lecturers and courses, which appears especially when asking lecturers: "So it about ...structure and connections" (Lecturers at education of radiography, p. 21). The framing and naming is acquired if the students should experience it meaningful: "We need a continuous thread in the subjects and courses" (quote from OS). A clear structure in the blended learning program thereby becomes a precondition for students coping and their SOC. In contrary it leads to confusion and a lack of 
understanding: "It is (blended learning) fine, but also confusing. We still really don't know what FlexVid (the blend) is" (quote from survey). If blended learning is perceived as confusing, then it indicates a lack of sufficient SOC which might hinder students access to learning of more transformative character, as it requires, that student can manage, comprehend and see the meaning, if they are to make challenges that involves development of their identity. If the designed learning environment makes them confused, then it probably will activate defense mechanisms to protection of students self, and no progression are immediately available.

5.2.3 Clarity. Clarity is a concept that is closely related to structure. The students' comprehensibility depends of the degree of clarity not only in aims and goals, but also in assignments. The student wish for clear guidance: "Cut it in a nutshell" (quote from OS) and "It is difficult, if the teacher doesn't 'puts it in a nutshell'...I think he (lecturer) makes far too open tasks, it put obstacles to us...he might limit it a bit". It becomes obvious that this lack of clarity affects students SOC if explications are blurred.

This is a matter of concern if students are to manage educational demands, otherwise it makes students insecure which might be a stressor: "I think the problem is that we didn't know, whether it was proper (the assignment)" (Teacher students, p.5). The lack of clearness is further problematized in relation to the available online learning platform: "Cannot find the assignments and homework at the learning platform" (quote from OS). The lack of clearness makes it hard for student to manage their online activities. The students' argumentation is that it could limit their process of learning. Thereby the resources available on the learning management system doesn't seem to afford the learning demands posed by the lecturers.

Another problem that seems obvious is the lack of clearness about the educational stations and their function, as they are perceived as invisible or of nonuse. If they aren't visible, useful and doesn't seem to be meaningful, then they cannot be managed or comprehended. And finally they doesn't influence the processes of learning, as intended. Clarity is therefore of significantly matter if structural and conceptual coherence are to be obtained.

5.2.4. Linkage. Linkage is also of great importance in the perceived sense of coherence among informants; especially the linkage between theory and practice seems to be of value for the students' comprehensibility. The relatedness of practice and examples from practice gives meaning, when dealing with concept in the academic field: "We need more practice related to the theoretical" (quote from OS). In return, the relation of theory to practice is also of significance, as students' experiences from practice are valued in the following theoretical education at UCN: “...to put the professional knowledge in the context of something they already know" (Lecturers at education of radiography, p.22). Theory becomes meaningful and comprehensible when it's connected to placement, and thereby the students are more able to manage the learning of new concepts and skills. Linkage is a central element in conceptual coherence as a condition for students SOC because linkage supports cohesion. As a student put it: “...I think you can see a connection to what you have learnt (in internship at the hospital)...what to make use for... and suddenly meaning arise, it is motivating" (Student radiography, p. 13). The fact that linkage creates meaningfulness makes the curricula oriented demands for combining theory and practice becomes worthy of investment and engagement.

5.2.5. Experience. Students' are carriers of experiences and predispositions when they enter the blended learning environment and thereby identity becomes a matter, both in transformative learning and in SOC. While identity is as a base of stability and a fundament in SOC [13], it is contrary in transformative learning, where development of identity is a condition for the transformation [15]. Thus, identity and experiences are both prerequisites and basis for learning and transformation.

The referential whole of students' experiences and attitudes are related to their management of educational affairs. On the one hand the students refers to their former experience with a kind of distancing; "I feel like, I am in high school again, and you feel, you are reduced to something, like you're 15 again" (Teacher students, p. 9) but on the other hand it is exactly a heritage, that they carry themselves: "I think when you come here as a freshman ... referring only back to how one's own teaching has been" (Practitioners at public school, p. 10). In implementation of new blended learning environments students referential kinds of habitus therefore must be taken into consideration, as possible constraints and a challenge. Experience is an internal condition that shapes students bibliography coherence and their sense of manageability, meaningfulness and comprehensibility. For instance experiences with classroom participation is something they have all experienced in previously education but the demands of studying at home and online appears to be less applicable. For example students might have a lot of experiences in the use of online media as leisure activities and pastime, but when it comes to using it for the purpose of studying they don't seem to be digital native.

So the blended learning approach faces some borders regarding students' previous experiences and bibliography coherence because a high degree of SOC might not fit into the blended program even 
though it could be very convenient for the students involved.

5.2.6. Convenience. Convenience is, opposed to stressors in the environment, an internal condition that promotes SOC. A student puts it like this: "It is easier to assess when facing each other, than if it's just something that is written (on-line)" (Teacher students', p.29). This quote illustrates that the wellknown face-to-face environment is preferred to the detriment of online learning. However this is not only for a matter for the students' perspective, as also lecturers problematize the suffering the experiences. In addition a practitioner accordingly adds: It's a mega hassle - with computers and everything like that" (Practitioners at municipal school, p. 11). It appears that the demands and stimuli coming from the implementation of more online learning activates stressors among the participant, but it is a condition that they have to face.

Convenience is therefore a matter of concern among students, and mentors also highlight the students' comforts, while a lecturer mentions the importance of facilitation: "It demands facilitation. There is no doubt, that the discussion is only good, if you are constantly scaffolding the persons involved" (Lecturers at education of radiography, p. 15). Even though scaffolding seems to be of obvious value [18], there might also be some value of pushing students away from their comfort zone. However, it acquires a high degree of confidence. So, it might be necessary to balance between overload and underload [13] in the zone of proximal development [16] if students shall achieve competences to develop the profession.

\section{Finding and discussion}

Even though, it is well documented that; structure as well as a clear context, transparency in education and training [19] and clarity between intensions and outcome [20] is of significant importance, it hasn't in prior educational research been related to the concept of SOC, as it is the case in this paper.

This research papers finding confirm the significance of SOC as a foundation for learning, transformative learning and knowledge development. Therefore, it becomes a matter of concern when implementing new kinds of model of learning, and as illustrated, particular blended learning in undergraduates' educations. The central plots that this paper emphasizes, regards the role of learning environments, structures, clarity, linkage, experience and convenience as a matter of concern when implementing blended learning in undergraduate educations.

This elaboration of plots furthermore illustrates the complexity of coherence and that it is not enough to look at coherence from a structural, conceptual and biographic perspective but it becomes necessary to take a look at the conditions of manageability, comprehensibility and meaningfulness from the derived perspectives of conditions as structure, clarity and linkage.

Furthermore the elaboration of the matter of the learning environment, experiences and convenience adds new dimension to the concept of coherence, whereas experiences and convenience is internal conditions, experience is an external condition, but both are shaping the bibliography coherence. Thus experience and convenience are both internal conditions in SOC they are also inhibitors in the context of students coping of the blended learning approach. The experience and convenience based framing of SOC thereby limit students access to the beneficial learning opportunities herein. The learning environment is similar a condition that might both inherent and scaffolding the external interaction processes of learning. However, in the case of convenience, there is obvious a need for pushing the nested convenience of the irrevocable fixed experiences, if students are to become developer of their own and the professions knowledge. This has to be managed through scaffolding in the zone of proximal development and with attention to stressors involved so that students can make progress of their biographic coherence.

In other words, if students are to benefit of the new blended learning environments they also must be pushed out of their comfort-zones without to many stressors involved. Therefore I stress that the implementation of new models in educations has to be balanced accordingly between under-load and overload. Coherence and SOC might give an indication of how conditions or offered approaches and initiatives are measured, and to which degree students manage to cope and make sense of the learning environments, but continuous assessments is needed along with the implementation of new designs and models thus with the extended perspective of SOC in mind.

\section{References}

[1] A.P. Rovai \& H. Jordan, "Blended Learning and Sense of Community: A comparative analysis with traditional and fully online graduate courses", International Review of Research in Open and Distance Learning, vol. 5, No. 2, August 2004.

[2] H. Schaap et al., "Students' personal professional theories in computer-based vocational education: the construction of personal knowledge through internalization and socialization", Journal of Vocational Education and Training, vol. 61. No. 4, 2009, pp. 481-494.

[3] D. Hisham et al., "Blended learning (BL) as pedagogical alternative to teach business communication 
course: Case study of UUM Diploma Program", Turkish Online Journal of Distance Education-TOJDE, vol.13, No 3, Article 21, July 2012.

[4] L. Lipponen, "Toward knowledge building discourse: From facts to explanations in primary students 'computer mediated discourse", Learning Environment Research, 3, 2000, pp. 179-199.

[5] N.G. Saunders et al., "Students perspectives: Responses to Internet Opportunities in a Distance learning Environment". Paper Presentation, The Annual Meeting of the Mid-West Research Association, Chicago, Illinois, 1997.

[6] K. Divaris et. al., "The academic environment: the students' perspective". European journal of Dental Education, 12, 2008, pp. 120-130.

[7] J. Voulo, "An exploration of the experiences of mature learners (post-qualified nurses) using a managed learning environment for the first time". Blended Learning In Practice, March, 2010, pp. 8-19.

[8] Garrison, D. R., \& N. D. Vaughan, Blended learning in higher education. Jossey-Bass Publisher,San Francisco, 2008.

[9] P. Grossman, M. McDonald \& M. Ronfeldt, "Constructing Coherence. Structural Predictors of Perceptions of Coherence in NYC Teacher Education Programs". Journal of Teacher Education, vol. 59, No. 4, 2008, pp. 273-287.

[10] J-C. Smeby \& K. Heggen, "Coherence and the development of professional knowledge and skills". Journal of Education and Work, vol. 27, No.1, 2014, pp. 71-91.

[11] M.A. McDonalds, "The integration of social justice in teachers education: Dimensions of prospective teachers' opportunities to learn", Journal if Teachers Education, vol. 56, No. 5, pp. 418-435

[12] Antonovsky, A., Unraveling The Mystery of Health How People Manage Stress and Stay Well, Jossey-Bass Publishers, San Francisco, 1987.

[13] M. Eriksson \& B. Linström, "Validity of Antonovsky's sense of coherence scale: a systematic review". Journal of Epidemiol Community Health, 59, 2005, pp. 460-466.

[14] C.A. Darling, L.M. McWey, S.N. Howard \& S.B. Olmstead, "College student stress: the influence of interpersonal relationship on sense of coherence". Stress and Health, 23, 2007, pp. 215-229.

[15] Illeris, K., Transformativ laering og identitet, Samfundslitteratur, Nayana Press, Gylling, 2013.

[16] Vygotsky, L., Mind in society: The development of higher psychological processes. Harvard University Press, Cambridge, 1978.
[17] Ricoeur, P., Time and Narrative, (vol. 1). (McLaughlin, K. \& Pellauer, D. Trans.) University of Chicago Press, Chicago, 1984.

[18] L. Buus, "Scaffolding Teachers Integrate Social Media Into a Problem-Based Learning Approach?" The Electronic Journal of e-Learning, vol. 10, No 1, 2012, pp. 13-22.

[19] DET., Blended learning, NSW Department of Education and training, 2003.

[20] Johnson, M., B. Cowie \& E. Khoo, Exploring elearning practices across the disciplines in a university environment. Teaching Learning Research Initiative Wellington, New Zealand, 2011. 